\title{
Volatility spillover among sector equity returns under structural breaks
}

\author{
Farooq Malik ${ }^{1}$ (D)
}

Accepted: 3 September 2021 / Published online: 16 September 2021

(C) The Author(s), under exclusive licence to Springer Science+Business Media, LLC, part of Springer Nature 2021

\begin{abstract}
Recent evidence suggests that ignoring structural breaks in volatility in financial asset returns can result in overestimation of volatility spillover among markets. This paper examines volatility spillover among major US equity sectors (i.e. Financial, Technology, Energy, Health, Consumer and Industrial) with bivariate GARCH models utilizing daily data from April 2006 to March 2021 after adjusting for volatility breaks. I find significantly less volatility spillover between sector returns after adjusting for detected volatility breaks into a bivariate GARCH model. I also show that after adding volatility breaks into a model the estimated hedge ratios change significantly and show considerably less variability over time, which can result in substantial savings in portfolio rebalancing costs.
\end{abstract}

Keywords Volatility spillover $\cdot$ Equity volatility $\cdot$ Structural breaks $\cdot$ GARCH

\section{JEL Classification G1}

\section{Introduction}

Sector index investing has become very prevalent over the last 2 decades due to the popularity of exchange traded funds. Returns on different equity sectors are generally strongly positively correlated over the long run but there can be substantial differences in the short run. For example, last year (2020), technology sector index increased by $40 \%$ while financial sector index decreased by $5 \%$. In the first quarter of this year (2021), we see an opposite pattern as technology sector index has increased by only $2 \%$ while financial sector index has gained by a sizable amount of $15 \%$. Not surprisingly, daily fluctuations in sector indexes are closely monitored by investors and policy makers. Therefore, there has been a substantial research which has explored the empirical and theoretical relationship among major equity sector returns.

The earlier line of literature had studied the empirical relationship among equity sectors in the level form. Notable studies include Ewing (2002) who used a vector auto-regression approach to examine the relationship among five major equity sectors. Using monthly data

Farooq Malik

farooq.malik@nau.edu

1 Franke College of Business, Northern Arizona University, Flagstaff, AZ 86011, USA 
from S\&P stock sector indexes from January 1988 to July 1997; he documents significant impact of shocks from one sector to other sector returns. Ewing et al. (2003) analyze the effects of unanticipated macroeconomic news on five major S\&P equity sector indexes using data after the 1987 crash period. Using generalized impulse response analysis, they show that equity sector returns are significantly more impacted by macroeconomic shocks relative to some predictable events. Meric et al. (2008) study the relationship among sector indexes in the US, UK, German, French, and Japanese stock markets during a bull and bear markets using Granger causality tests. They report that during a bull market investors are better off if they invest in the same sector in a different country rather than investing in different sectors within the same country. In contrast, the sectors of different countries are highly correlated during a bear market, which restricts diversification benefits across countries.

However, there are many credible reasons which suggest that the volatility from one equity sector may spillover to other sectors. Three lines of thoughts have emerged in the literature which can explain these volatility spillover effects. First, volatility spillovers may result from hedging across markets carried out by investors due to changes in common information across sectors which instantaneously changes expectations. Fleming et al. (1998) provide a model that shows how hedging combined with sharing of common information across markets will lead to volatility spillover across financial markets over time. Second, mean and volatility spillover could be due to financial contagion, where a shock to one financial market may cause a change in asset prices in other financial markets. Kodres and Pritsker (2002) give a multiple-asset rational expectations model to explain contagion in financial markets. They show that investors transmit shocks among financial markets by modifying their portfolio exposure to different macroeconomic risks. They argue that the amount of financial contagion is primarily determined by how sensitive the market is to the underlying shared macroeconomic risk factors and the extent of information asymmetry among financial markets. Third, Ross (1989) proposed a model where volatility in financial asset returns depends upon the rate of information flow. Since one would expect different rates of information flow across sectors and also the time used in processing such information may vary across sectors, thus we should expect different volatility patterns across sectors over time.

Although there has been an explosion in the literature on the studies of volatility spillovers between financial markets, it is interesting to note that there have been relatively few studies that have examined volatility spillover among equity sector returns. The first study on this topic was conducted by Hassan and Malik (2007) who used a multivariate GARCH model to model volatility among major US equity sector indexes. They show a significant transmission of volatility among sectors and document the corresponding economic implications. ${ }^{1}$ Recent studies include, Nguyen et al. (2020), who examine the volatility spillover across industries and its dependence on the inter-industry business linkages. They document significant cross-industry volatility spillovers, which they attribute to the strength of the trade relationship between industries. Mensi et al. (2021) examine the dynamic asymmetric volatility connectedness among ten US stock sectors. They provide evidence of time-varying spillovers among US stock sectors and they show that these spillovers gain intensity during major economic, energy and geopolitical events.

\footnotetext{
1 In a related study, Malik and Ewing (2009) show substantial transmission of shocks and volatility between oil prices and US equity sector returns.
} 
There are many methods to estimate time-varying volatility in financial asset prices. One such popular method is a GARCH model, which is built on an assumption that volatility is produced from a stable GARCH process. This assumption is seriously questioned as widespread empirical evidence suggests that there are structural breaks (shifts) in the unconditional variance of stock returns (Starica and Granger 2005; Hood and Malik 2018). Starica and Granger (2005) underscore the need to adjust for structural breaks in volatility of financial asset prices. Ewing and Malik (2005) were the first to account for such structural breaks to correctly estimate the volatility spillover across markets within a bivariate GARCH model. They provide empirical evidence which shows that volatility spillover is reduced between small cap and large cap US stock returns when breaks in volatility are added in the bivariate GARCH model. A later study by Marcelo et al. (2008) further documents that volatility spillover effects are substantially reduced when volatility breaks are adjusted for in the small and large cap Spanish equities. Similarly, Huang (2012) shows that there is bidirectional volatility spillover between stock returns of the UK and the US but this spillover effect is disappeared after volatility breaks in the bivariate GARCH model are accounted for. Recently, Caporin and Malik (2020) document using comprehensive Monte Carlo simulations that induced structural breaks in volatility across two independent return series will display significant (spurious) volatility spillover effects when estimated with popularly used bivariate GARCH models. Given this widespread evidence, this paper examines the volatility spillover between equity sector returns adjusting for structural breaks in volatility using the framework originally proposed by Ewing and Malik (2005). To the best of my knowledge, this is the first paper which studies the volatility spillover between US sector equity returns after accounting for structural breaks in volatility.

Specifically, this paper studies the volatility spillover between six major US equity sector stock returns (i.e. Financial, Technology, Energy, Health, Consumer and Industrial) using daily data from April 2006 to March 2021. First, I document significant bidirectional volatility transmission between sectors in all six bivariate GARCH models (i.e. financialtechnology, financial-energy, technology-energy, health-industrial, health-consumer and industrial-consumer) if breaks are ignored, which is consistent with Hassan and Malik (2007). Then using modified iterative cumulative sum of squares (ICSS) algorithm proposed by Inclan and Tiao (1994), I show significant structural breaks in volatility in all six sector returns, some corresponding to major news event like the COVID-19. After incorporating these volatility breaks into the GARCH model, I find significant reduction in volatility spillover and only find unidirectional volatility spillover (i.e. only one sector transmits volatility to the other sector but not vice versa). Specifically, I find that after incorporating breaks in the model, volatility from financial sector no longer spillover to technology sector, volatility from energy sector no longer spillover to financial sector, volatility from energy sector no longer spillover to technology sector, volatility from health sector no longer spillover to industrial sector, volatility from consumer sector no longer spillover to health sector, and volatility from consumer sector no longer spillover to health sector These findings could be due to hedging by investors across these sectors and show an estimation bias in the standard bivariate GARCH models as they have a tendency to overestimate the volatility spillovers when volatility breaks are not accounted for as documented by Caporin and Malik (2020). I also report that when structural breaks are added into a model, estimated hedge ratios change significantly and show considerably less variability. This less variability in hedge ratios can result in substantial savings for investors as they no longer need to frequently rebalance their portfolios. I also extend the work of Caporin and Malik (2020) by conducting and reporting my own set of Monte Carlo simulations with parameter settings which are more suitable to the data used in this paper. 
These results are important for forecasting volatility in sector returns and will improve our understanding of the broader equity markets. Furthermore, since many financial assets are traded in the market based on these sector equity indexes, it is imperative for investors to understand how volatility is transmitted across these sectors so they can make correct adjustments to their portfolios and correctly price financial assets. My findings are also useful for policy makers as accurately estimating volatility spillovers are very important to devise policies to curtail a spread of risk across sectors especially during a period of market turmoil.

\section{Empirical methodology}

In this section, I describe the method I use to find significant structural breaks in volatility of sector returns, followed by describing the bivariate GARCH models used in the study. Then, I provide a description on how volatility breaks are incorporated into the bivariate GARCH model to correctly estimate the volatility spillover between sector returns.

\subsection{Detecting structural breaks in volatility}

Hillebrand (2005) conclusively shows that if a GARCH process undergoes a break then this will result in a break in the unconditional variance of the return series. Inclan and Tiao (1994) give cumulative sums of squares (IT) statistic which can be used to test the null hypothesis of a constant unconditional variance against the alternative hypothesis that there is a break in the unconditional variance. Their original test was designed for a return generating process which is independently distributed.

However, Sanso et al. (2004) demonstrate that the statistic proposed by Inclan and Tiao (1994) when applied to a series with dependent process (like GARCH) will result in substantial size distortions. They propose a non-parametric correction to the original IT statistic so it can be applied to a dependent process like GARCH. Inclan and Tiao (1994) also propose an iterated cumulative sums of squares (ICSS) algorithm which can be used on the IT statistic for detecting unlimited number of breaks in the unconditional variance of a return series. This algorithm when used on the modified IT statistic (with nonparametric correction) circumvents the issues that arise when the original IT statistic is used on a dependent process. In this study, I use the modified ICSS algorithm (i.e. using original ICSS algorithm to the modified IT statistic) as proposed by Sanso et al. (2004) to find breaks in the unconditional variance of sector index returns. Sanso et al. (2004) show through detailed theoretical proofs, Monte Carlo simulations and real-world data that their proposed method (which I use in this paper) correctly identifies structural breaks. I employ the standard 5\% level of significance for testing multiple breaks in the unconditional variance of each sector index return series. ${ }^{2}$

\subsection{Bivariate GARCH model}

The mean equation estimated for each sector return series is given as

\footnotetext{
${ }^{2}$ Rapach and Strauss (2008) provide a comprehensive explanation of the methodology used in this paper as they use this method as well to detect significant structural breaks in volatility of exchange rates.
} 


$$
R_{t}=\mu+\rho R_{t-1}+\varepsilon_{t}
$$

where $\mathrm{R}_{\mathrm{t}}$ represents the individual sector index return and $\varepsilon_{t}$ is assumed to have a normal distribution with a mean of zero. Following Aggarwal et al. (1999), I use an AR(1) process in the above equation as Q-statistic showed significant autocorrelation in each of the sector index returns. I applied the modified ICSS algorithm on the residuals of the individual sector returns to detect structural breaks in variance.

With respect to the bivariate GARCH $(1,1)$ model, I estimate the benchmark BEKK parameterization proposed by Engle and Kroner (1995) which is given as

$$
H_{t+1}=C^{\prime} C+B^{\prime} H_{t} B+A^{\prime} \varepsilon_{t} \varepsilon_{t}^{\prime} A
$$

For my bivariate case, $C$ is a $2 \times 2$ lower triangular matrix and $B$ is a $2 \times 2$ matrix which indicates how current volatility is impacted by the volatility in the last time period. $A$ is a $2 \times 2$ matrix which shows how current volatility is impacted by the squared errors in the last time period. For my bivariate case, the total estimated number of parameters would be eleven.

The above volatility equation can be expanded as

$$
\begin{gathered}
h_{11, t+1}=c_{11}^{2}+b_{11}^{2} h_{11, t}+2 b_{11} b_{21} h_{12, t}+b_{21}^{2} h_{22, t}+a_{11}^{2} \varepsilon_{1, t}^{2}+2 a_{11} a_{21} \varepsilon_{1, t} \varepsilon_{2, t}+a_{21}^{2} \varepsilon_{2, t}^{2} \\
h_{22, t+1}=c_{12}^{2}+c_{22}^{2}+b_{12}^{2} h_{11, t}+2 b_{12} b_{22} h_{12, t}+b_{22}^{2} h_{22, t}+a_{12}^{2} \varepsilon_{1, t}^{2}+2 a_{12} a_{22} \varepsilon_{1, t} \varepsilon_{2, t}+a_{22}^{2} \varepsilon_{2, t}^{2}
\end{gathered}
$$

Equations (3) and (4) captures how shocks and volatility spillover exist across the two sector return series over a period of time. ${ }^{3}$ I use the quasi-maximum likelihood estimation using robust standard errors as proposed by Bollerslev and Wooldridge (1992).

\subsection{Bivariate GARCH model with structural breaks in variance}

Following Ewing and Malik (2005), I augment the bivariate GARCH model with dummy variables to account for breaks in volatility as

$$
\mathrm{H}_{\mathrm{t}+1}=\mathrm{C}^{\prime} \mathrm{C}+\mathrm{B}^{\prime} \mathrm{H}_{\mathrm{t}} \mathrm{B}+\mathrm{A}^{\prime} \varepsilon_{\mathrm{t}} \varepsilon_{\mathrm{t}}^{\prime} \mathrm{A}+\sum_{\mathrm{i}=1}^{\mathrm{n}} \mathrm{D}_{\mathrm{i}}^{\prime} \mathrm{X}_{\mathrm{i}}^{\prime} \mathrm{X}_{\mathrm{i}} \mathrm{D}_{\mathrm{i}} .
$$

Equation (5) differs from Eq. (2) because of the extra term $D_{i}$ which is a $2 \times 2$ square diagonal parameter matrix and $X_{i}$ is a $1 \times 2$ row vector of dummies where $n$ is the number of volatility breaks identified by the modified ICSS algorithm. The first (second) element in $\mathrm{X}_{\mathrm{i}}$ row vector denotes the dummy for the first (second) series. If a volatility break is identified at time " $t$ " in a series, then the corresponding element in $X_{i}$ will take a value of 1 from time " $t$ " afterwards and a value of 0 before time " $t$ ".

\footnotetext{
${ }^{3}$ It is pertinent to note that the coefficient terms in Eqs. (3) and (4) depend on the parameters from Eq. (2) in a non-linear fashion. Thus, I follow Ewing and Malik (2005) to compute the standard errors for these coefficient terms by using a first-order Taylor expansion around the mean.
} 
Table 1 Descriptive statistics

\begin{tabular}{lllllll}
\hline & Financial & Technology & Energy & Health & Consumer & Industrial \\
\hline Mean & 0.000068 & 0.000507 & -0.000018 & 0.000344 & 0.000279 & 0.000262 \\
Median & 0.000541 & 0.001127 & 0.000384 & 0.000758 & 0.000499 & 0.000785 \\
Minimum & -0.18639 & -0.14983 & -0.22417 & -0.10528 & -0.09690 & -0.12155 \\
Maximum & 0.172013 & 0.11461 & 0.169604 & 0.11713 & 0.08835 & 0.12000 \\
SD & 0.02101 & 0.01455 & 0.01918 & 0.01130 & 0.00949 & 0.01427 \\
Skewness & -0.22762 & -0.32471 & -0.68899 & -0.23050 & -0.17040 & -0.52261 \\
Kurtosis & 18.4579 & 13.0000 & 18.8934 & 13.9752 & 17.3015 & 12.0832 \\
Jarque-Bera & $37,617.06$ & $15,795.59$ & $40,030.75$ & $18,980.13$ & $32,189.67$ & $13,149.17$ \\
\hline
\end{tabular}

Sample includes daily sector index returns from April 1, 2006 to March 31, 2021. Total number of observations is 3775. Jarque-Bera statistic detects if a series deviates from a normal distribution and in all three sector index returns above I reject the null hypothesis of normality at $1 \%$ level. The correlation between Financial-Technology sector returns was 0.72 , the correlation between Financial-Energy sector returns was - 0.08 and correlation between Technology-Energy sector returns was -0.07 . The correlation between Health-Industrial sector returns was 0.77 , the correlation between Health-Consumer sector returns was -0.13 and correlation between Industrial-Consumer sector returns was -0.12

\section{Data}

I use daily closing prices from the sector equity data from April 1, 2006 to March $31,2021 .{ }^{4}$ I use the $S \& P$ Dow Jones sector indexes and the data was obtained from Bloomberg. In my analysis, I specifically study the following six major sector indexes: financials, (information) technology, energy, health, consumer (staples) and industrial. ${ }^{5}$ These $S \& P$ Dow Jones sector indexes are widely used by investors and policy makers to track movements of these sectors. Additionally, these sector indexes are publicly reported to provide a measure for individual sector performance. These indexes represent a large number of major firms and industries within the US. The financial sector index comprises of big corporations dealing with banks, asset management, insurance companies, consumer finance, mortgage companies, etc. The (information) technology sector index is made up of companies which deal in telecommunications, software, semiconductors, computer (hardware and software), internet, etc. The energy sector index comprises of major US companies who are engaged in the energy sector like oil refining, oil exploration, etc. Health index includes health-care providers and services, companies that manufacture and distribute health-care equipment and supplies, and health-care technology companies including pharmaceutical and biotechnology companies. Consumer staples index covers businesses that are less sensitive to economic cycles, including manufacturers and distributors of food, beverages, and producers of non-durable household goods and personal products including food and drug retailers. Industrial index includes manufacturers and distributors of capital goods such as building products, electrical equipment and machinery, and aerospace and defense including

\footnotetext{
4 I have used 15 years of most recent daily data to be consistent with earlier relevant studies mentioned in this paper.

5 I selected these six sectors based on the popularity in the news media and these are the ones most studied based on the cited literature including Hassan and Malik (2007).
} 
providers of commercial services such as construction and engineering, printing, environmental services, human resource services, research and consulting services, and transportation services. In line with previous research, I use log returns as all series in level form possessed a unit root.

Table 1 displays descriptive statistics for each of the sector return series. As can be seen from Table 1, all six of the sector returns series shows excessive kurtosis which shows that a GARCH model would be the appropriate choice to estimate volatility. All six sector returns series show negative skewness. As expected, Jarque-Bera statistic for all six sector returns rejects normality hypothesis at the $1 \%$ significance level. The correlation between Financial-Technology sector returns was 0.72 , the correlation between Financial-Energy sector returns was -0.08 and correlation between Technology-Energy sector returns was - 0.07. The correlation between Health-Industrial sector returns was 0.77, the correlation between Health-Consumer sector returns was -0.13 and correlation between IndustrialConsumer sector returns was -0.12 .

\section{Empirical results}

The modified ICSS algorithm identified 9 structural breaks in the financial sector returns, 5 breaks in the technology sector returns, 11 breaks in the energy sector returns, 2 structural breaks in the health sector returns, 5 breaks in the consumer sector returns and 12 breaks in the industrial sector returns. These detected breaks are presented in Table 2 and displayed in Figs. 1, 2, 3, 4, 5 and 6. Two things are clearly noticeable from these detected breaks. First, all sectors (except health sector) experience an upward shift of more than double magnitude with the advent of financial crisis of 2007-2008. Second, around Feb 20, 2020 all sectors (except consumer) experience more than doubling of volatility which coincides with the market uncertainty induced by the COVID-19. Although these findings are not surprising but Caporin and Malik (2020) document if markets experiencing a common volatility break are more likely to show a significant spurious volatility spillover effect if these breaks are not accounting for.

Next, I estimate the volatility spillover between sector index returns using a bivariate GARCH model without adjusting for volatility breaks. Panel A of Table 3 presents the results for the financial and technology sector. I find that both financial sector and technology sector volatility is significantly impacted by its own 'news' and volatility (see the coefficients of $h_{11}$ and $\varepsilon_{1}^{2}$ in the first equation and coefficients of $h_{22}$ and $\varepsilon_{2}^{2}$ in the second equation as statistically significant at the $5 \%$ significance level). The results also show a significant volatility spillover from each sector to the other sector. This result is consistent with previous research findings of Hassan and Malik (2007) as they show significant volatility spillover across sectors. A clear implication of these results would be that investors in either sector need to keep a close eye on the other sector movement as bidirectional volatility (risk) spillover exists.

Next, I estimate the bivariate GARCH model after adjusting for identified volatility breaks and the results are given in Panel B of Table 3. Like earlier results, sectors returns are impacted by its own 'news' and volatility from prior time period. However, it is important to note that there is now only a unidirectional volatility spillover. In other words, volatility in technology sector significantly affects volatility of financial sector but financial sector has an insignificant impact on volatility of technology sector. This result is consistent with Caporin and Malik (2020), who argue that if volatility breaks are present and 
Table 2 Detected volatility breaks

\begin{tabular}{|c|c|c|c|}
\hline Series & Break points & Time period & SD \\
\hline \multirow[t]{10}{*}{ Financial } & \multirow[t]{10}{*}{9} & April 1, 2006-July 27, 2006 & 0.009262 \\
\hline & & July 28, 2006-Feb 21, 2007 & 0.005357 \\
\hline & & Feb 22, 2007-March 20, 2007 & 0.015124 \\
\hline & & March 21, 2007-July 22, 2007 & 0.008682 \\
\hline & & July 23, 2007-July 2, 2008 & 0.022503 \\
\hline & & July 3, 2008-May 17, 2009 & 0.061743 \\
\hline & & May 18, 2009-Aug 1, 2012 & 0.018331 \\
\hline & & Aug 2, 2012-Aug 18, 2015 & 0.008674 \\
\hline & & Aug 19, 2015-Feb 20, 2020 & 0.011001 \\
\hline & & Feb 21, 2020-March 31, 2021 & 0.028214 \\
\hline \multirow[t]{6}{*}{ Technology } & \multirow[t]{6}{*}{5} & April 1, 2006-Oct 17, 2007 & 0.009767 \\
\hline & & Oct $18,2007-$ Sept 11,2008 & 0.015966 \\
\hline & & Sept 12, 2008-Dec 7, 2008 & 0.044282 \\
\hline & & Dec 8, 2008-April 20, 2009 & 0.025676 \\
\hline & & April 21, 2009-Feb 20, 2020 & 0.011312 \\
\hline & & Feb 21, 2020-March 31, 2021 & 0.025186 \\
\hline \multirow[t]{12}{*}{ Energy } & \multirow[t]{12}{*}{11} & April 1, 2006-Oct 17, 2007 & 0.013941 \\
\hline & & Oct $18,2007-$ Sept 4, 2008 & 0.019550 \\
\hline & & Sept 5, 2008-Nov 27, 2008 & 0.066360 \\
\hline & & Nov 28, 2008-June 2, 2009 & 0.027199 \\
\hline & & June 3, 2009-July 28, 2011 & 0.013864 \\
\hline & & July 29, 2011-Dec 18, 2011 & 0.026529 \\
\hline & & Dec 19, 2011-June 23, 2013 & 0.010711 \\
\hline & & June 24, 2013-Oct 6, 2014 & 0.008040 \\
\hline & & Oct 7, 2014-Nov 30, 2016 & 0.015793 \\
\hline & & Dec 1, 2016-Jan 24, 2018 & 0.008434 \\
\hline & & Jan 25, 2018-Feb 19, 2020 & 0.013402 \\
\hline & & Feb 20, 2020-March 31, 2021 & 0.037720 \\
\hline \multirow[t]{3}{*}{ Health } & \multirow[t]{3}{*}{2} & April 1, 2006-Feb 20, 2020 & 0.010508 \\
\hline & & Feb 21, 2020-April 5, 2020 & 0.045509 \\
\hline & & April 6, 2020-March 31, 2021 & 0.011446 \\
\hline \multirow[t]{6}{*}{ Consumer } & \multirow[t]{6}{*}{5} & April 1, 2006-July 5, 2007 & 0.005571 \\
\hline & & July 6, 2007-Sept 14, 2008 & 0.009065 \\
\hline & & Sept 15, 2008-Nov 27, 2008 & 0.032355 \\
\hline & & Nov 28, 2008-Jan 27, 2009 & 0.013164 \\
\hline & & Jan 28, 2009-March 19, 2009 & 0.018389 \\
\hline & & March 20, 2009-March 31, 2021 & 0.008763 \\
\hline
\end{tabular}


Table 2 (continued)

\begin{tabular}{|c|c|c|c|}
\hline Series & Break points & Time period & SD \\
\hline \multirow[t]{13}{*}{ Industrial } & 12 & April 1, 2006-Aug 15, 2006 & 0.009330 \\
\hline & & Aug 16, 2006-July 24, 2007 & 0.006857 \\
\hline & & July 25, 2007-Sept 11, 2008 & 0.014568 \\
\hline & & Sept 12, 2008-Dec 1, 2008 & 0.043556 \\
\hline & & Dec 2, 2008-May 31, 2009 & 0.027736 \\
\hline & & June 1, 2009-Nov 8, 2009 & 0.014692 \\
\hline & & Nov 9, 2009-July 24, 2011 & 0.012296 \\
\hline & & July 25, 2011-Dec 19, 2011 & 0.023565 \\
\hline & & Dec 20, 2011-Aug 17, 2015 & 0.008661 \\
\hline & & Aug 18, 2015-July 7, 2016 & 0.011466 \\
\hline & & July 8, 2016-Jan 30, 2018 & 0.006256 \\
\hline & & Feb 1, 2018-Feb 25, 2020 & 0.011095 \\
\hline & & Feb 26, 2020-March 31, 2021 & 0.024285 \\
\hline
\end{tabular}

Time periods detected by modified ICSS algorithm. Sample period is from April 1, 2006 to March 31, 2021

\section{Daily Financial Sector Index Returns}

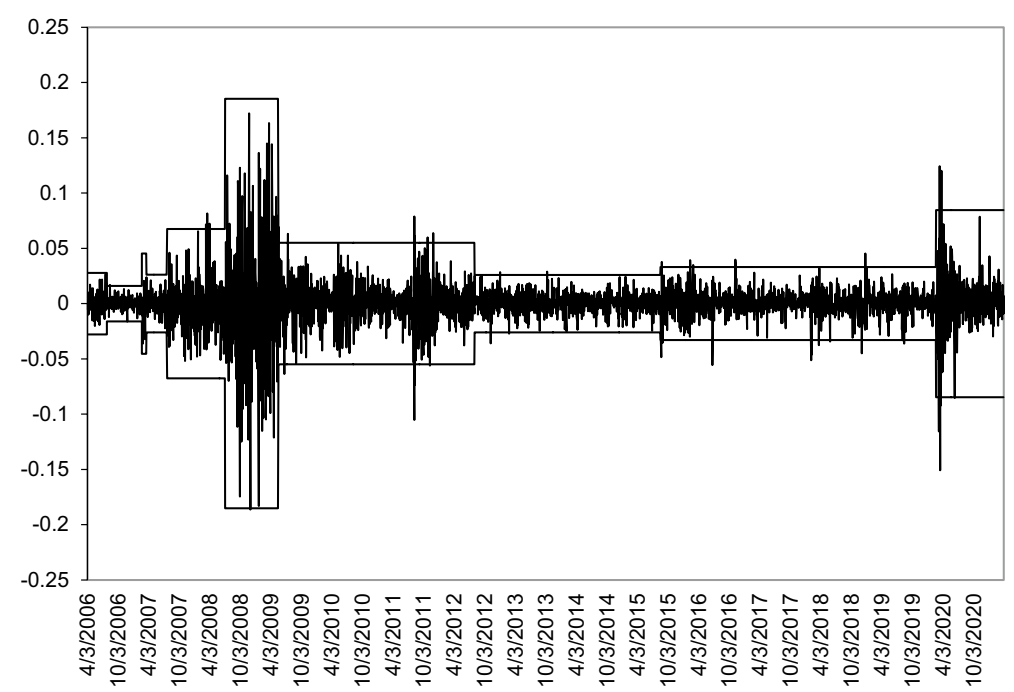

Fig. 1 Daily financial sector index returns. Note Bands drawn at \pm 3 standard deviations and volatility breaks are identified by modified ICSS algorithm

ignored then volatility spillover effects are exaggerated due to a bias which is present in popular bivariate GARCH models. This lack of volatility spillover across sectors could also be due to hedging performed by investors across markets. 


\section{Daily Technology Sector Index Returns}

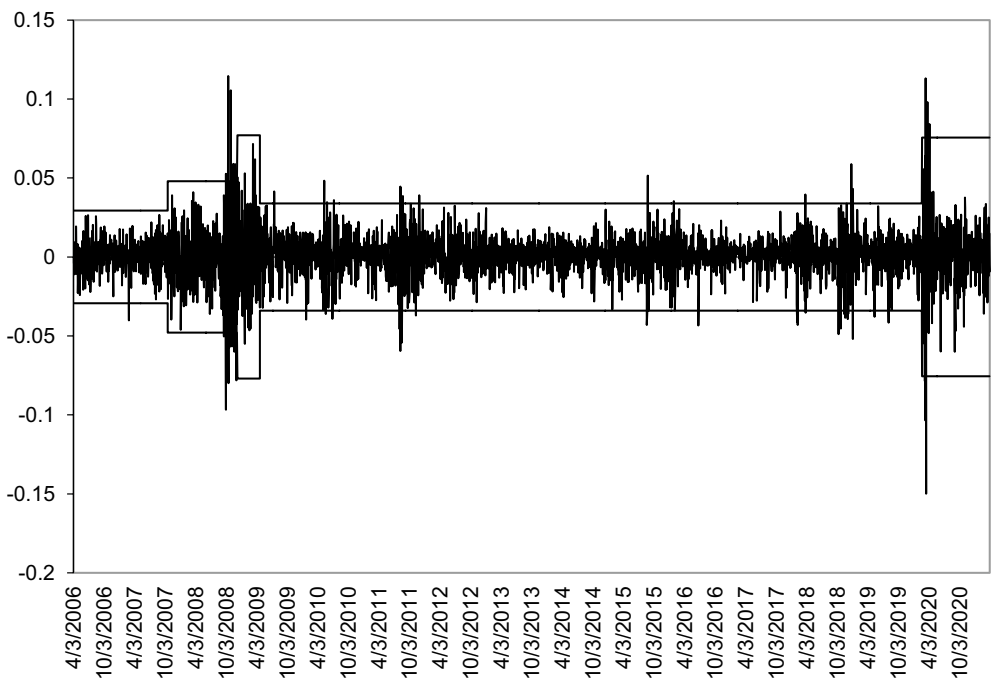

Fig. 2 Daily technology sector index returns. Note Bands drawn at \pm 3 standard deviations and volatility breaks are identified by modified ICSS algorithm

\section{Daily Energy Sector Index Returns}

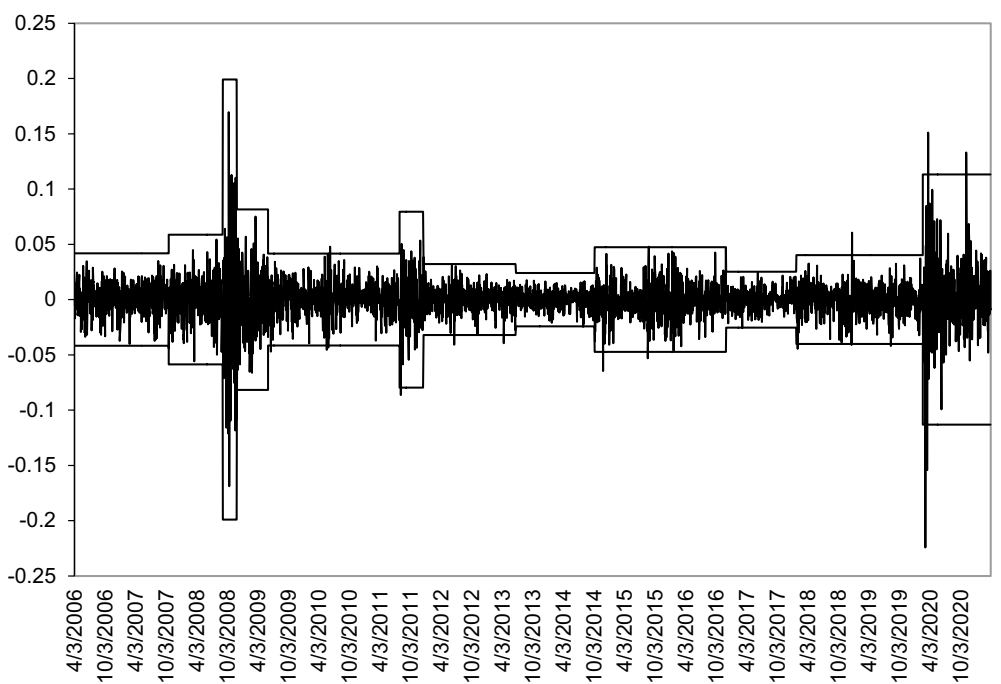

Fig. 3 Daily energy sector index returns. Note Bands drawn at \pm 3 standard deviations and volatility breaks are identified by modified ICSS algorithm

I also conduct more analysis to see if my above findings carry over to other sector combinations. Consequently, I model the financial and energy sector. The results ignoring breaks are presented in Panel A of Table 4 while results after accounting for 


\section{Daily Health Sector Index Returns}

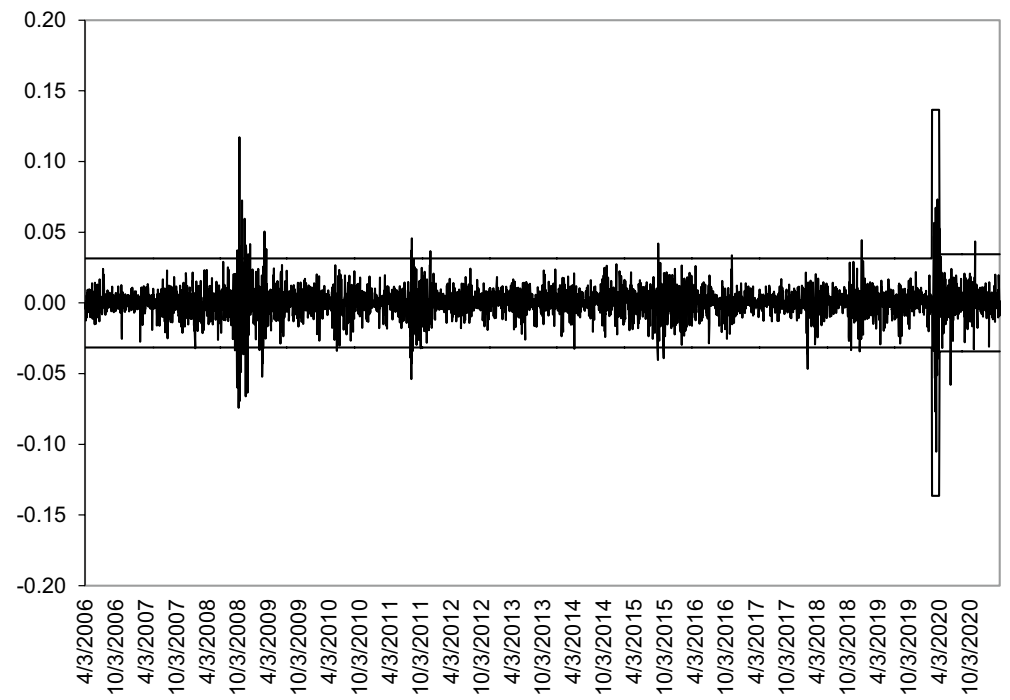

Fig. 4 Daily health sector index returns. Note Bands drawn at \pm 3 standard deviations and volatility breaks are identified by modified ICSS algorithm

\section{Daily Consumer Sector Index Returns}

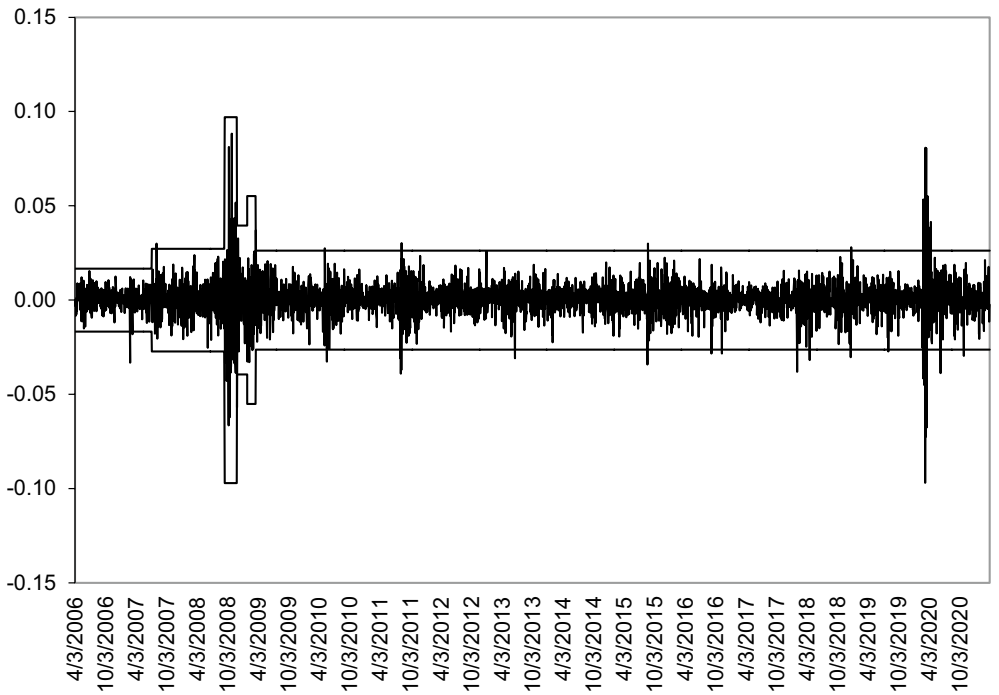

Fig. 5 Daily consumer sector index returns. Note Bands drawn at \pm 3 standard deviations and volatility breaks are identified by modified ICSS algorithm

breaks are shown in Panel B of Table 4. I find same results as reported earlier; that is ignoring breaks show significant bidirectional volatility spillover effects and once breaks are accounted for then I find unidirectional volatility spillover effects. Table 5 


\section{Daily Industrial Sector Index Returns}

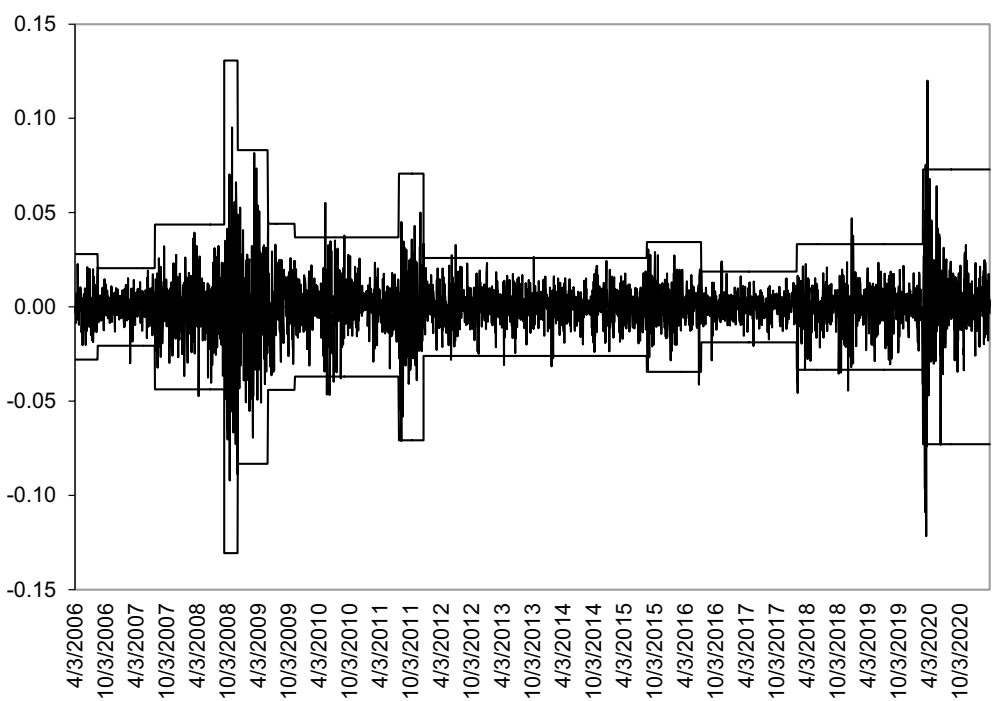

Fig. 6 Daily industrial sector index returns. Note Bands drawn at \pm 3 standard deviations and volatility breaks are identified by modified ICSS algorithm

Table 3 (A) Bivariate GARCH model without volatility breaks for financial and technology Sector and (B) bivariate GARCH model with volatility breaks for financial and technology Sector

Panel A

Financial sector variance equation

$h_{11, t+1}=5.99 \times 10^{-8}+1.848 h_{11, t}-2.855 h_{12, t}+1.102 h_{22, t}+0.063 \varepsilon_{1, t}^{2}+0.026 \varepsilon_{1, t} \varepsilon_{2, t}+0.002 \varepsilon_{2, t}^{2}$
(0.35)
(25.10)
$(-6.56)$
(3.68)
(3.15)
(1.72)

Technology sector variance equation

$h_{22, t+1}=2.14 \times 10^{-6}+0.775 h_{11, t}-2.363 h_{12, t}+1.801 h_{22, t}+0.002 \varepsilon_{1, t}^{2}-0.035 \varepsilon_{1, t} \varepsilon_{2, t}+0.112 \varepsilon_{2, t}^{2}$

(8.77)

(5.14)

$(-10.44)$

(24.51)

(0.89)

$(-1.47)$

Panel B

Financial sector variance equation

$h_{11, t+1}=1.62 \times 10^{-6}+0.928 h_{11, t}-0.089 h_{12, t}+0.002 h_{22, t}+0.063 \varepsilon_{1, t}^{2}+0.064 \varepsilon_{1, t} \varepsilon_{2, t}+0.016 \varepsilon_{2, t}^{2}$
(2.73)
(42.01)
$(-4.92)$
(2.55)
(3.51)
(6.84)

Technology sector variance equation

$h_{22, t+1}=4.93 \times 10^{-6}+2.34 \times 10^{-7} h_{11, t}+0.0008 h_{12, t}+0.843 h_{22, t}+0.0001 \varepsilon_{1, t}^{2}+0.007 \varepsilon_{1, t} \varepsilon_{2, t}+0.116 \varepsilon_{2, t}^{2}$
(8.18)
$(0.01)$
(0.03)
(36.24)
$(0.13)$
$(0.26)$

$\mathrm{h}_{11}$ denotes volatility of financial sector returns and $\mathrm{h}_{22}$ denotes volatility of technology sector returns. T-values are reported beneath the coefficients. $L R=2\left[L\left(\Theta_{1}\right)-L\left(\Theta_{0}\right)\right]$, where $L\left(\Theta_{1}\right)$ and $L\left(\Theta_{0}\right)$ are the maximum log likelihood values attained from the model with and without volatility breaks, respectively. Thus LR is calculated as $2(23,815.44-23,625.69)=379.5$, which is significant at $1 \%$ level suggesting that the model with breaks gives a significantly better fit 
Table 4 (A) Bivariate GARCH model without volatility breaks for financial and energy sector and (B) bivariate GARCH model with volatility breaks for financial and energy sector

Panel A

Financial sector variance equation

(3.36) (6.31) (-12.15)

(15.94)

(3.66)

$(-8.87)$

Energy sector variance equation

$h_{22, t+1}=5.08 \times 10^{-6}+0.139 h_{11, t}+0.681 h_{12, t}+0.832 h_{22, t}+0.0009 \varepsilon_{1, t}^{2}+0.006 \varepsilon_{1, t} \varepsilon_{2, t}+0.012 \varepsilon_{2, t}^{2}$

(2.02)

(4.36)

(9.69)

(38.84)

$(0.65)$

(1.20)

(1.99)

Panel B

Financial sector variance equation

$h_{11, t+1}=1.23 \times 10^{-6}+0.627 h_{11, t}+0.140 h_{12, t}+0.007 h_{22, t}+0.056 \varepsilon_{1, t}^{2}-0.258 \varepsilon_{1, t} \varepsilon_{2, t}+0.2966 \varepsilon_{2, t}^{2}$
(1.44)
(7.07)
(2.26)
(1.28)
(2.90)
$(-3.52)$

Energy sector variance equation

$h_{22, t+1}=4.47 \times 10^{-6}+0.020 h_{11, t}-0.270 h_{12, t}+0.911 h_{22, t}+0.034 \varepsilon_{1, t}^{2}+0.013 \varepsilon_{1, t} \varepsilon_{2, t}+0.001 \varepsilon_{2, t}^{2}$
(5.23)
(2.09)
$(-4.27)$
(24.71)
(2.18)
$(0.48)$

$\mathrm{h}_{11}$ denotes volatility of financial sector returns and $\mathrm{h}_{22}$ denotes volatility of energy sector returns. T-values are reported beneath the coefficients. $L R=2\left[L\left(\Theta_{1}\right)-L\left(\Theta_{0}\right)\right]$, where $L\left(\Theta_{1}\right)$ and $L\left(\Theta_{0}\right)$ are the maximum $\log$ likelihood values attained from the model with and without volatility breaks, respectively. Thus LR is calculated as $2(21,529.07-21,481.83)=94.48$, which is significant at $1 \%$ level suggesting that the model with breaks gives a significantly better fit

Table 5 (A) Bivariate GARCH model without volatility breaks for technology and energy sector and (B) bivariate GARCH model with volatility breaks for technology and energy sector

Panel A

Technology sector variance equation

(1.02) (3.66) (6.88)

$(16.75) \quad(0.12) \quad(-0.25)$

(8.83)

Energy sector variance equation

$h_{22, t+1}=1.14 \times 10^{-5}+1.42 h_{11, t}-0.882 h_{12, t}+0.136 h_{22, t}+0.022 \varepsilon_{1, t}^{2}+0.012 \varepsilon_{1, t} \varepsilon_{2, t}+0.001 \varepsilon_{2, t}^{2}$

(3.52)

(15.37)

$(-11.85)$

(5.25)

(1.27)

(1.19)

\section{Panel B}

Technology sector variance equation

$h_{11, t+1}=3.21 \times 10^{-5}+0.151 h_{11, t}-0.120 h_{12, t}+0.023 h_{22, t}+0.0003 \varepsilon_{1, t}^{2}-0.022 \varepsilon_{1, t} \varepsilon_{2, t}+0.372 \varepsilon_{2, t}^{2}$
(5.60)
(3.52)
$(-3.09)$
(1.61)
$(0.20)$
$(-0.40)$

Energy sector variance equation

$h_{22, t+1}=1.96 \times 10^{-6}+0.322 h_{11, t}+1.00 h_{12, t}+0.781 h_{22, t}+0.001 \varepsilon_{1, t}^{2}+0.003 \varepsilon_{1, t} \varepsilon_{2, t}+0.002 \varepsilon_{2, t}^{2}$ $(0.34)$

(2.90)

(7.02)

(13.14)

$(0.42)$

(0.63)

$\mathrm{h}_{11}$ denotes volatility of technology sector returns and $\mathrm{h}_{22}$ denotes volatility of energy sector returns. T-values are reported beneath the coefficients. $L R=2\left[L\left(\Theta_{1}\right)-L\left(\Theta_{0}\right)\right]$, where $L\left(\Theta_{1}\right)$ and $L\left(\Theta_{0}\right)$ are the maximum log likelihood values attained from the model with and without volatility breaks, respectively. Thus LR is calculated as $2(22,275.94-22,181.88)=94.06$, which is significant at $1 \%$ level suggesting that the model with breaks gives a significantly better fit 
Table 6 (A) Bivariate GARCH model without volatility breaks for health and industrial sector and (B) bivariate GARCH model with volatility breaks for health and industrial sector

Panel A

Health sector variance equation

(5.74)

(25.04)

$(-38.61)$

(42.44)

(4.30)

(4.16)

(1.55)

Industrial sector variance equation

$h_{22, t+1}=2.88 \times 10^{-6}+0.286 h_{11, t}+0.601_{12, t}+0.316 h_{22, t}+0.0004 \varepsilon_{1, t}^{2}+0.014 \varepsilon_{1, t} \varepsilon_{2, t}+0.102 \varepsilon_{2, t}^{2}$

(4.50)

(16.33)

(66.85)

(16.13)

(0.409)

$(0.85)$

Panel B

Health sector variance equation

$h_{11, t+1}=3.51 \times 10^{-5}+0.376 h_{11, t}-1.299 h_{12, t}+1.121 h_{22, t}+0.060 \varepsilon_{1, t}^{2}+0.032 \varepsilon_{1, t} \varepsilon_{2, t}+0.004 \varepsilon_{2, t}^{2}$
(7.94)
(2.86)
$(-4.71)$
(12.77)
(4.62)
(3.46)

Industrial sector variance equation

$h_{22, t+1}=2.53 \times 10^{-6}+0.260 h_{11, t}+0.591 h_{12, t}+0.335 h_{22, t}+0.0009 \varepsilon_{1, t}^{2}+0.019 \varepsilon_{1, t} \varepsilon_{2, t}+0.098 \varepsilon_{2, t}^{2}$
(5.77)
(1.82)
(11.90)
(2.60)
(0.56)
(1.17)

(7.65)

$\mathrm{h}_{11}$ denotes volatility of health sector returns and $\mathrm{h}_{22}$ denotes volatility of industrial sector returns. T-values are reported beneath the coefficients. $L R=2\left[L\left(\Theta_{1}\right)-L\left(\Theta_{0}\right)\right]$, where $L\left(\Theta_{1}\right)$ and $L\left(\Theta_{0}\right)$ are the maximum $\log$ likelihood values attained from the model with and without volatility breaks, respectively. Thus LR is calculated as $2(25,383.36-25,370.25)=26.22$, which is significant at $1 \%$ level suggesting that the model with breaks gives a significantly better fit

Table 7 (A) Bivariate GARCH model without volatility breaks for health and consumer sector and (B) bivariate GARCH model with volatility breaks for health and consumer sector

\section{Panel A}

\section{Health sector variance equation}

$h_{11, t+1}=9.03 \times 10^{-6}+0.046 h_{11, t}-0.275 h_{12, t}+0.407 h_{22, t}+0.0007 \varepsilon_{1, t}^{2}+0.046 \varepsilon_{1, t} \varepsilon_{2, t}+0.762 \varepsilon_{2, t}^{2}$
(3.15)
(2.45)
$(-4.61)$
(6.27)
(0.315)
(0.63)

Consumer sector variance equation

$h_{22, t+1}=9.21 \times 10^{-6}+0.420 h_{11, t}+0.771 h_{12, t}+0.353 h_{22, t}+0.0005 \varepsilon_{1, t}^{2}-0.001 \varepsilon_{1, t} \varepsilon_{2, t}+0.001 \varepsilon_{2, t}^{2}$

(3.22)

(9.11)

(12.11)

(6.14)

(0.46)

$(-0.67)$

$(0.50)$

Panel B

Health sector variance equation

$h_{11, t+1}=2.71 \times 10^{-5}+0.022 h_{11, t}+0.006 h_{12, t}+0.0004 h_{22, t}+0.001 \varepsilon_{1, t}^{2}+0.063 \varepsilon_{1, t} \varepsilon_{2, t}+1.010 \varepsilon_{2, t}^{2}$
(22.88)
(2.00)
(0.26)
(0.13)
(0.38)
(0.76)

(26.08)

Consumer sector variance equation

$h_{22, t+1}=1.06 \times 10^{-7}+0.138 h_{11, t}-0.659 h_{12, t}+0.782 h_{22, t}+0.001 \varepsilon_{1, t}^{2}-0.001 \varepsilon_{1, t} \varepsilon_{2, t}+0.0005 \varepsilon_{2, t}^{2}$
(0.08)
(3.54)
$(-9.25)$
(13.44)
(0.74)
$(-0.46)$

$\mathrm{h}_{11}$ denotes volatility of health sector returns and $\mathrm{h}_{22}$ denotes volatility of consumer sector returns. T-values are reported beneath the coefficients. $L R=2\left[L\left(\Theta_{1}\right)-L\left(\Theta_{0}\right)\right]$, where $L\left(\Theta_{1}\right)$ and $L\left(\Theta_{0}\right)$ are the maximum $\log$ likelihood values attained from the model with and without volatility breaks, respectively. Thus LR is calculated as $2(25,896.93-25,789.88)=214.10$, which is significant at $1 \%$ level suggesting that the model with breaks gives a significantly better fit 
Table 8 (A) Bivariate GARCH model without volatility breaks for industrial and consumer sector and (B) bivariate GARCH model with volatility breaks for industrial and consumer sector

Panel A

Industrial sector variance equation

$h_{11, t+1}=6.90 \times 10^{-6}+0.340_{11, t}+0.686 h_{12, t}+0.346 h_{22, t}+0.00001 \varepsilon_{1, t}^{2}+0.008 \varepsilon_{1, t} \varepsilon_{2, t}+1.10 \varepsilon_{2, t}^{2}$
(1.80)
(3.42)
(5.68)
(6.46)
$(0.05)$
(0.10)

Consumer sector variance equation

$h_{22, t+1}=8.33 \times 10^{-6}+0.089 h_{11, t}-0.463 h_{12, t}+0.603 h_{22, t}+0.018 \varepsilon_{1, t}^{2}+0.022 \varepsilon_{1, t} \varepsilon_{2, t}+0.006 \varepsilon_{2, t}^{2}$
(2.18)
(4.85)
$(-11.57)$
(13.31)
(1.76)
(1.87)

Panel B

Industrial sector variance equation

$h_{11, t+1}=1.84 \times 10^{-5}+0.059 h_{11, t}-0.075 h_{12, t}+0.024 h_{22, t}+0.00002 \varepsilon_{1, t}^{2}-0.013 \varepsilon_{1, t} \varepsilon_{2, t}+1.64 \varepsilon_{2, t}^{2}$

$\begin{array}{lllll}(5.63) & (2.60) & (-1.12) & (0.58) & (0.06)\end{array}$

Consumer sector variance equation

$h_{22, t+1}=1.34 \times 10^{-6}+0.124 h_{11, t}+0.608 h_{12, t}+0.743 h_{22, t}+0.0005 \varepsilon_{1, t}^{2}-0.0005 \varepsilon_{1, t} \varepsilon_{2, t}+0.0001 \varepsilon_{2, t}^{2}$
$(0.41)$
(4.60)
(13.21)
(9.39)
$(0.53)$
$(-0.31)$

$h_{11}$ denotes volatility of industrial sector returns and $h_{22}$ denotes volatility of consumer sector returns. T-values are reported beneath the coefficients. $L R=2\left[L\left(\Theta_{1}\right)-L\left(\Theta_{0}\right)\right]$, where $L\left(\Theta_{1}\right)$ and $L\left(\Theta_{0}\right)$ are the maximum log likelihood values attained from the model with and without volatility breaks, respectively. Thus LR is calculated as $2(25,054.05-24,969.35)=169.40$, which is significant at $1 \%$ level suggesting that the model with breaks gives a significantly better fit

shows the results for the technology and energy sector and I confirm the same results as well. Specifically, I find bidirectional volatility spillover if breaks are ignored and unidirectional spillover results if breaks are adjusted for in the model. These same results carry over to other sector combinations such as health and industrial (Table 6), health and consumer (Table 7) and industrial and consumer (Table 8).

The significance of structural breaks in volatility can be additionally tested by the commonly used likelihood ratio (LR) statistic, which is computed as $L R=2\left[L\left(\Theta_{1}\right)-L\left(\Theta_{0}\right)\right]$, where $L\left(\Theta_{1}\right)$ and $L\left(\Theta_{0}\right)$ are values acquired via maximum log-likelihood from the GARCH model with and without volatility breaks, respectively. This statistic has a distribution given by $\chi^{2}$ where the degrees of freedom equal the number of constraints imposed in the model with breaks relative to the model without breaks and this statistic is reported in the notes of each table of the bivariate GARCH estimation results. As can be seen, in all cases, the null hypothesis of no change in volatility can be rejected at the $1 \%$ level of significance. This implies that, in all three cases, the model with volatility breaks provides a significantly better fit relative to the model without breaks.

Finally, I did the standard series of diagnostics on residuals on both set of models (with and without breaks) for each sector combination (results not report for the sake of brevity but can be provided on request). It is pertinent to note that no issues were identified in all cases. This highlights the significance of explicitly testing for volatility breaks in the underlying return series before modelling as normal residual diagnostics are not able to identify any problems. 


\section{Economic implications: hedge ratios}

Investors and policy makers want to know if shocks and volatility spillover exist across different sectors so they can make optimal decisions. There are many practical economic implications of my results as accurately estimating volatility is vital for decisions involving pricing of financial assets, risk management and portfolio allocation (see Kroner and $\mathrm{Ng}, 1998$ ). In the interest of space, here I only focus on the impact that breaks have on estimated optimal hedge ratios. Lien and Yang (2010) show that risk exposure in currencies can be optimally hedged using currency futures if breaks in unconditional variance are accounted for in a bivariate GARCH framework. Consequently, proper estimation of volatility spillover is required for making correct hedging decisions.

Hedging across markets is widely practiced in real life by investors to minimize their risk exposure. Kroner and Sultan (1993) argue that an investor should short $\$ \beta$ of asset 1 to minimize risk of a $\$ 1$ portfolio that have a long position in asset 2 . The time-variant hedge ratio $\beta$ is computed as $\beta_{t}=\frac{h_{12 t}}{h_{22 t}}$, where $h_{12 t}$ is the conditional covariance between asset 1 and asset 2 while $h_{22 t}$ is the conditional variance of asset 2 returns. As can be seen that this hedge ratio is dependent on how volatility spillover across assets evolves over time and clearly incorrectly estimating the volatility spillover will give poor hedging efficiency. Since cross market hedging is typically conducted using two assets which are positively correlated, so I use financial and technology sector in my example. ${ }^{6}$ I find that the average estimated hedge ratio ignoring the volatility break was 0.37 with a standard deviation of 0.97 , but after accounting for breaks you get a hedge ratio of 0.77 with a standard deviation of 0.26 . These results show that not only hedge ratios change substantially in the presence of breaks but ignoring them results in far greater variability. It is important to note that that more variability in estimated hedge ratios can potentially result in a significant increases in portfolio rebalancing costs as traders need to adjust their portfolio more frequently. It is documented in the literature that large variability in the estimated hedge ratios results in poor hedging performance as compared to a simple unconditional (constant) hedge ratio (see Fan et al., 2016; Lien, 2010). My findings are in line with simulation results of Caporin and Malik (2020) as they show that structural breaks induce changes in estimated hedge ratios and the resulting ratios shows more variability.

\section{Monte Carlo simulations}

In this section, I extend the work of Caporin and Malik (2020) by using Monte Carlo simulations and showing that ignoring structural breaks induces spurious spillover effect. I also show that adding a dummy variable eliminates this bias as that is the strategy I use in my earlier empirical analysis. ${ }^{?}$

I generate two univariate GARCH series using $h_{t}=\omega+\alpha \varepsilon_{t-1}^{2}+\beta h_{t-1}$, each with $\omega=0.000008, \alpha=0.1$ and $\beta=0.85$. This gives us an annual variance of $20 \%$. These values are in line with the US stock market over the last 15 years of daily data. Then I induce a

\footnotetext{
${ }^{6}$ Other sector combinations gave same overall conclusion that after accounting for breaks the hedge ratios change substantially and exhibit less variability.

7 I only discuss the base model of simulations here in the interest of space and detailed simulation results are available on request.
} 
break in the middle of the sample (by increasing $\omega$ to 0.000032) such that in the second half of sample, variance doubles to $40 \%$. This variance break size magnitude is typical of variance breaks that I found in the US stock market over the last 15 years of daily data. I use an overall sample size of 4000, which gives us 2000 observations on each side so we do not have to be concerned about the small sample bias. I use RATS software to estimate MGARCH by using 20 initial iterations of simplex algorithm then switching to BFGS algorithm. This is the standard way most researchers estimate MGARCH models. Using 5000 simulations, I found that the $\mathrm{b}_{21}$ and $\mathrm{b}_{12}$ element of BEKK parameters from Eqs. (3) and (4) was statistically significant $30 \%$ of the time using robust standard errors. This shows that researchers would find spurious volatility spillover $30 \%$ of the time although both series are generated independently. It is interesting to note that other simulations showed (not reported here) that bias substantially increases when I incorporate correlation among series, break size is increased or multiple breaks are incorporated.

Finally, I re-estimate the same model 5000 times on the simulated returns with structural breaks but augment my model with dummy variable corresponding to the induced break point, replicating my approach in my earlier empirical analysis. I found the spurious volatility spillover effect to reduce from 30 to $1 \%$, which is equal to the level of significance I used. These numbers show that adding dummy variable to account for structural breaks in volatility yields correct estimate for the volatility spillover effect. ${ }^{8}$

\section{Conclusion}

This paper studies volatility spillover between major US equity sector returns utilizing bivariate GARCH models using daily data from April 2006 to March 2021. The modified ICSS algorithm is employed to identify significant structural breaks in volatility in sector index returns. My results show significant volatility spillover in both directions in each of the six estimated bivariate GARCH models if volatility breaks are ignored. However, after adjusting for structural breaks in volatility, I find significantly less volatility spillover effects and only one sector affects volatility of the other. I also report that average hedge ratios dramatically change and show less variability when volatility breaks are added in the bivariate GARCH model. The evidence suggests that my findings are possibility driven by cross-sector hedging by investors and possibly due to an estimation bias in the bivariate GARCH models because they typically overestimate the degree of volatility spillovers in the presence of structural breaks.

As quite a few financial assets are traded in the market based on these sector indexes, it is important that investors and policy makers make an accurate estimate of the extent of the volatility spillover that exists across these major sectors returns over time. I make a timely contribution as the importance of volatility spillover effects across financial markets have taken center stage due to the impact that the looming COVID-19 crisis has on financial markets across the globe.

\footnotetext{
${ }^{8}$ It is pertinent to note that Caporin and Malik (2020) primarily report their findings using the Wald Test but also show that their results hold even if they use a Lagrange Multiplier test.
} 


\section{References}

Aggarwal R, Inclan C, Leal R (1999) Volatility in emerging markets. J Financ Quant Anal 34:33-55

Bollerslev T, Wooldridge JM (1992) Quasi-maximum likelihood estimation and inference in dynamic models with time-varying covariances. Econom Rev 11:143-172

Caporin M, Malik F (2020) Do structural breaks in volatility cause spurious volatility transmission? J Empir Financ 55:60-82

Engle RF (1982) Autoregressive conditional heteroskedasticity with estimates of the variance of united kingdom inflation. Econometrica 50:987-1007

Engle R, Kroner K (1995) Multivariate simultaneous generalized ARCH. Econom Theor 11:122-150

Ewing BT (2002) The transmission of shocks among S\&P indexes. Appl Financ Econ 12:285-290

Ewing BT, Malik F (2005) Re-examining the asymmetric predictability of conditional variances: the role of sudden changes in variance. J Bank Finance 29:2655-2673

Ewing BT, Forbes SM, Payne JE (2003) The effects of macroeconomic shocks on sector-specific returns. Appl Econ 35:201-207

Fan R, Li H, Park SY (2016) Estimation and hedging effectiveness of time-varying hedge ratio: nonparametric approaches. J Futur Mark 36:968-991

Fleming J, Kirby C, Ostdiek B (1998) Information and volatility linkages in the stock, bond, and money markets. J Financ Econ 49:111-137

Hassan SA, Malik F (2007) Multivariate GARCH modeling of sector volatility transmission. Q Rev Econ Finance 47:470-480

Hillebrand E (2005) Neglecting parameter changes in GARCH Models. J Econom 129:121-138

Hood M, Malik F (2018) Estimating downside risk in stock returns under structural breaks. Int Rev Econ Financ 58:102-112

Huang PK (2012) Volatility transmission across stock index futures when there are structural changes in return variance. Appl Financ Econ 22:1603-1613

Inclan C, Tiao GC (1994) Use of cumulative sums of squares for retrospective detection of changes of variance. J Am Stat Assoc 89:913-923

Kodres LE, Pritsker M (2002) A rational expectations model of financial contagion. J Finance 57:768-799

Kroner KF, Ng VK (1998) Modeling asymmetric comovements of asset returns. Rev Financ Stud 11:817-844

Kroner KF, Sultan J (1993) Time varying distributions and dynamic hedging with foreign currency futures. J Financ Quant Anal 28:535-551

Lien D (2010) A note on the relationship between the variability of the hedge ratio and hedging performance. J Futur Mark 30:1100-1104

Lien D, Yang L (2010) The effects of structural breaks and long memory on currency hedging. J Futur Mark 30:607-632

Malik F, Ewing BT (2009) Volatility transmission between oil prices and equity sector returns. Int Rev Financ Anal 3:95-100

Marcelo M, Quiros JLM, Quiros MDM (2008) Sudden shifts in variance in the Spanish market: persistence and spillover effects. Appl Financ Econ 18:115-124

Mensi W, Nekhili R, Vo XV, Suleman T, Kang SH (2021) Asymmetric volatility connectedness among US stock sectors. N Am J Econ Finance 56:101327

Meric I, Ratner M, Meric G (2008) Co-movements of sector index returns in the world's major stock markets in bull and bear markets: portfolio diversification implications. Int Rev Financ Anal 17:156-177

Nguyen LXD, Mateut S, Chevapatrakul T (2020) Business-linkage volatility spillovers between US industries. J Bank Finance 111:105699

Rapach DE, Strauss JK (2008) Structural breaks and GARCH models of exchange rate volatility. J Appl Econom 23:65-90

Ross SA (1989) Information and volatility: the no-arbitrage martingale approach to timing and resolution irrelevancy. J Finance 44:1-17

Sanso A, Arrago V, Carrion JL (2004) Testing for change in the unconditional variance of financial time series. Rev Econom Financ 4:32-53

Starica C, Granger CWJ (2005) Nonstationarities in stock returns. Rev Econ Stat 87:503-522

Publisher's Note Springer Nature remains neutral with regard to jurisdictional claims in published maps and institutional affiliations. 